\title{
Phage-host associations in a full-scale activated sludge plant during sludge bulking
}

\author{
Ruyin Liu ${ }^{1,2} \cdot$ Rong $\mathrm{Qi}^{2} \cdot$ Juan Wang ${ }^{2}$ Y Yu Zhang ${ }^{1,2} \cdot$ Xinchun Liu ${ }^{1,2}$. \\ Simona Rossetti ${ }^{3}$. Valter Tandoi ${ }^{3}$ Min Yang ${ }^{1,2}$
}

Received: 23 May 2017 / Revised: 7 July 2017 / Accepted: 17 July 2017 /Published online: 29 July 2017

(C) Springer-Verlag GmbH Germany 2017

\begin{abstract}
Sludge bulking, a notorious microbial issue in activated sludge plants, is always accompanied by dramatic changes in the bacterial community. Despite large numbers of phages in sludge systems, their responses to sludge bulking and phage-host associations during bulking are unknown. In this study, high-throughput sequencing of viral metagenomes and bacterial 16S rRNA genes were employed to characterize viral and bacterial communities in a sludge plant under different sludge conditions (sludge volume index (SVI) of 180, 132, and $73 \mathrm{ml} / \mathrm{g}$ ). Bulking sludges (SVI > $125 \mathrm{ml} / \mathrm{g}$ ) taken about 10 months apart exhibited similar bacterial and viral composition. This reflects ecological resilience of the sludge microbial community and indicates that changes in viral and bacterial populations correlate closely with each other. Overgrowth of "Candidatus Microthrix parvicella" led to filamentous bulking, but few corresponding viral genotypes were identified. In contrast, sludge viromes were characterized by numerous contigs associated with "Candidatus Accumulibacter phosphatis," suggesting an abundance of corresponding phages in the sludge viral community. Notably,
\end{abstract}

Electronic supplementary material The online version of this article (doi:10.1007/s00253-017-8429-8) contains supplementary material, which is available to authorized users.

Yu Zhang

zhangyu@rcees.ac.cn

1 College of Resources and Environment, University of Chinese Academy of Sciences, Beijing, China

2 Research Center for Eco-Environmental Sciences, Chinese Academy of Sciences, 18 Shuangqing Road, Haidian District, Beijing 100085, China

3 Water Research Institute, CNR, Monterotondo (RM), Italy while nitrifiers (mainly Nitrosomonadaceae and Nitrospiraceae) declined significantly along with sludge bulking, their corresponding viral contigs were identified more frequently and with greater abundance in the bulking viromes, implying that phage-mediated lysis might contribute to the loss of autotrophic nitrifiers under bulking conditions.

Keywords Sludge bulking · Phage-host association · Viral metagenome analysis $\cdot 16 \mathrm{~S}$ rRNA gene pyrosequencing

\section{Introduction}

Biological wastewater treatment is one of the most important biotechnological applications, wherein bacteria play key roles in the removal of pollutants. In activated sludge treatment plants, free viral particles (mainly phages) are believed to be approximately tenfold more numerous than bacterial cells with an estimated concentration of over $10^{8}$ particles per microliter (Tamaki et al. 2012; Wu and Liu 2009). Due to the predation pressure exerted by phages, bacterial fitness is measured by their adaptation not only to available nutrients but also to the biotic environment (Shapiro and Kushmaro 2011). With such high numbers of viral particles, the bacterial diversity and abundance in sludge processes could be continuously regulated by phage predation (Shapiro et al. 2010), thereby possibly affecting the treatment performance (Barr et al. 2010). Therefore, it is important to understand phage-host associations and predict changes in viral populations in activated sludge processes. However, most studies on viral ecology are carried out in aquatic, especially oceanic (Pagarete et al. 2013; Sakowski et al. 2014; Suttle 2007), ecosystems and knowledge about the viral community in complex activated sludge systems is scarce. 
Sludge bulking is a common problem encountered in the operation of activated sludge plants, characterized by the sludge with a high sludge volume index (SVI) that does not settle properly (Jenkins et al. 2004). Bulking is always accompanied by significant changes in bacterial community structures (Wang et al. 2014). Most frequently, overgrowth of many filamentous bacteria, such as "Candidatus Microthrix parvicella" (henceforth referred to as Microthrix parvicella), Haliscomenobacter hydrossis, or Nocardiaform-like organisms, may cause the bulking problem (Henze et al. 2008). Some of these filamentous bacteria (e.g., M. parvicella) are also responsible for the solid-liquid separation problem in sludge foaming, that is the generation of stable foam on the surface of aerated reactors (de los Reyes 2010, Rossetti et al. 2005). Assuming continuous phage-host interactions in activated sludge processes (Shapiro and Kushmaro 2011), viral communities are expected to change dramatically along with sludge bulking, thus providing a good opportunity to explore phage-host associations. To date, despite the vast numbers of phages in sludge systems, the response of viral communities to sludge bulking is still unknown.

Plaque assay is the traditional method for studying phages and their hosts. Given that most bacteria in wastewater treatment systems, such as "Candidatus Accumulibacter phosphatis" (henceforth referred to as Accumulibacter phosphatis), filamentous M. parvicella, and nitrifying bacteria, are still unculturable or hard-to-culture, their corresponding phages are not easily detected by plaque assay. In contrast, molecular methods developed over the past decade, especially metagenomics, are providing culture-independent ways to examine viral communities in various ecosystems (Parsley et al. 2010; Tamaki et al. 2012). Furthermore, recent advances in bioinformatics have allowed us to link phage genotypes to their hosts based on the obtained metagenomic data. For example, clustered regularly interspaced short palindromic repeats (CRISPR) and genetic homology between phage and bacterial genome sequences can provide significant signals for phage-host classification (Edwards et al. 2016).

In this study, we collected three activated sludge samples with different settling properties (SVI of 180, 132, and $73 \mathrm{ml} / \mathrm{g}$ ) from a full-scale activated sludge plant in north China where Microthrix-associated filamentous bulking periodically occurs during the cold season (Fig. S1) (Wang et al. 2014). Metagenomic analysis was employed to identify viral communities of free virus-like particles and to predict phage-host associations, while changes in bacterial communities were examined by $16 \mathrm{~S}$ ribosomal RNA (rRNA) gene pyrosequencing (Edwards et al. 2016; Modi et al. 2013; Stern et al. 2012). Results from this study will improve our understanding of phagehost associations in activated sludge processes.

\section{Materials and methods}

\section{Description of activated sludge plant and sample collection}

A full-scale activated sludge plant in Beijing with a conventional $\mathrm{A}^{2} / \mathrm{O}$ (anaerobic/anoxic/aerobic) process was used in this study. It treats approximately 200,000 tons of domestic wastewater per day. The plant operates normally during summer and autumn with good sludge settleability. Sludge bulking (SVI > $125 \mathrm{ml} / \mathrm{g}$, Fig. S1) generally occurs in winter and spring when water temperature drops. The most serious sludge bulking occurs in February and March when the lowest water temperature appears $\left(T \leq 15^{\circ} \mathrm{C}\right)$. Bulking had no adverse effects on the chemical oxygen demand (COD) and the phosphorus removal, whereas the nitrification got worse during sludge bulking (Wang et al. 2014). In this study, biological samples were collected in 2012-5 (recovering sludge at the end stage of bulking with an SVI value of $132 \mathrm{ml} / \mathrm{g}$; referred to as ASR), 2012-9 (normal sludge with an SVI value of $73 \mathrm{ml} / \mathrm{g}$; referred to as ASN), and 2013-3 (serious bulking sludge with an SVI value of $180 \mathrm{ml} / \mathrm{g}$; referred to as ASB) (Fig. S1). At each sampling time, about 50-L sludge liquor taken from the aerobic unit was collected for microbial analysis, and transported back to the laboratory within $2 \mathrm{~h}$.

\section{Bacterial 16S rRNA gene pyrosequencing and data processing}

Each sludge sample was divided into two replicates, which were processed in parallel through all the following steps. After centrifuging $(10,000 \times g, 10 \mathrm{~min}), 0.25 \mathrm{~g}$ (wet weight) of sludge was used for DNA extraction. Total DNA was extracted using the FastDNA SPIN kit for soil (MP Biomedicals, USA) facilitated with the FastPrep-24 bead beater system according to the manufacturer's instructions. Bacterial $16 \mathrm{~S}$ rRNA gene was PCR amplified from genomic DNA using primers 8F and 533R (Benitez-Paez et al. 2013), with barcodes incorporated into the $5^{\prime}$ end of primer 533R. After purification of the PCR products on a $1.5 \%(w / v)$ agarose gel, pyrosequencing was performed by using a Roche 454 FLX instrument (Roche Diagnostics, Indianapolis, IN, USA).

QIIME v1.9 was used to process the pyrosequencing data, which was deposited in the NCBI SRA database with an accession number SRP097570 (Caporaso et al. 2010). The QIIME pipeline picked operational taxonomic units (OTUs) at a $97 \%$ similarity threshold using the UCLUST method, and performed taxonomical classification using the RDP classifier with default settings. Furthermore, the pyrosequences were compared against a bulking and foaming bacteria (BFB) database using the MOTHUR software (Guo and Zhang 2012; Schloss et al. 2009). Taxonomic assignment of sequences was based on the naïve Bayesian approach with a confidence threshold of $80 \%$ (Wang et al. 2007). 


\section{Generation of viral metagenome}

Sludge samples (about 20-L sludge liquor) were shaken vigorously for $30 \mathrm{~min}$ to disperse sludge flocs, pre-filtered with Glassfibre prefilter (Sartorius, Germany) to remove large-size particles, and then filtered with nitrocellulose membrane ( $0.45 \mu \mathrm{m}$, Sartorius, Germany) to remove small-size particles and bacteria. The filtrate was applied onto a tangential flow filtration (TFF) system mounted with a $0.22-\mu \mathrm{m}$ Hydrosart Cassettes (Sartorius, Germany). The permeate containing mainly virus particles was concentrated to a final volume of $200 \mathrm{ml}$ with the TFF system mounted with a $30-\mathrm{kDa}$ Hydrosart Cassettes (Sartorius, Germany) (Tamaki et al. 2012). Non-virus nucleic acids were eliminated from the retentate by nuclease digestion (final concentrations of $10 \mu \mathrm{g} / \mathrm{ml}$ DNase I, $10 \mu \mathrm{g} / \mathrm{ml}$ RNase A, and $5 \mathrm{mM} \mathrm{MgCl}_{2}$; $3 \mathrm{~h}$ at $37^{\circ} \mathrm{C}$ ). Virions were recovered by polyethylene glycol precipitation and collected by centrifugation at $13,000 \times g$ for $15 \mathrm{~min}$ before being resuspended in $5 \mathrm{ml}$ of TE buffer $(10 \mathrm{mM}$ Tris [pH 8.0], $1 \mathrm{mM}$ EDTA) (Petrovski et al. 2011). Chloroform was added ( 0.2 volumes) to the concentrated viral samples to remove contaminated microbial cells (note: some viruses sensitive to chloroform, such as Corticoviridae, Plasmaviridae, Asfraviridae, and Inoviridae, might also be destroyed) (Thurber et al. 2009). The aqueous phase was treated with nuclease digestion again to remove residual host and bacterial DNA. Finally, the samples were passed through a $0.22-\mu \mathrm{m}$ filter (Sartorius, Germany) to ensure no procedural contamination was introduced.

DNA was isolated from the concentrated viral samples using SDS-proteinase $\mathrm{K}$ as described by Petrovski et al. (2011). The viral genomic DNA was sheared using the Covaris ${ }^{\mathrm{TM}}$ Covaris $\mathrm{S} 220$ System (Applied Biosystems) resulting in fragment insert sizes of about 180 nucleotides. Libraries were prepared and sequenced on the Illumina HiSeq ${ }^{\mathrm{TM}} 2000$ platform at Novogene (Beijing, China).

\section{General analysis of virome}

After removing low-quality reads (the percentage of the lowquality bases of quality value $\leq 5$ is more than $50 \%$ in a read) as well as reads with adaptors or reads in which unknown bases are more than $10 \%$, the sequence data obtained was deposited in the NCBI SRA database (accession number SRP097361). The clean data was uploaded to the MGRAST server (mgm4564469.3, mgm4564470.3, and mgm4564471.3) (Meyer et al. 2008) and processed using the default trimming and filtering settings to allow comparison to different data sets. Taxonomic assignments were performed by comparing data to the M5NR database (Wilke et al. 2012). Functions encoded by the viromes were determined by comparing the viral metagenomic sequences against the SEED subsystems, the NOG database, and the KEGG database, respectively.

\section{Viral contig assembly and analysis}

SOAPdenovo v1.0.6 was employed to assembly the sequencing reads ( $\mathrm{Li}$ et al. 2010). The assembled viromes were deposited in the MG-RAST (mgm4561901.3, mgm4561902.3, and mgm4561903.3). Using the Metavir server (Roux et al. 2014), both tBLASTx-based and nucleotide-composition-based (triand tetranucleotide) similarities were computed to compare viromes in their entirety rather than only their small known fraction. All reads were mapped back to each contigs by endto-end alignment with Bowtie2 (Langmead and Salzberg 2012), and the resulting alignments were used to calculate the relative abundance (mapped reads/total reads) of a contig in each virome.

\section{Prediction of phage-host association}

Genetic homology and CRISPR analysis are effective computational approaches to predict phage-host associations (Edwards et al. 2016; Modi et al. 2013; Stern et al. 2012). According to Edwards et al. (2016), nucleotide searches are more accurate than protein searches for host prediction based on the genetic homology between phage and bacterial genomes. Therefore, we used a BLASTn search (a cutoff $E$ value of $1 \mathrm{e}^{-90}$ ) of the assembled contigs against a database including NCBI reference bacterial genomes as well as the genomes of M. parvicella Bio17-1 and RN1. For each viral genotype (contig), bacteria with the longest alignment length were considered as potential hosts (Edwards et al. 2016). Then, we checked whether the matching fragments fell in the putative prophage regions within the host's genomes by using PHASTER (Arndt et al. 2016). Furthermore, the genetic homology between the assembled contigs and NCBI reference viral genomes was also computed by BLASTn with a strict cutoff $E$-value of $1 \mathrm{e}^{-90}$ to identify the contigs homologous to known viruses.

Spacer sequences in a bacterial CRISPR locus can provide identifiable signatures for phage-host classification. CRISPR analysis has been applied to predict phage-host associations in diverse environments (Edwards et al. 2016; Stern et al. 2012). In this study, CRISPR spacers in M. parvicella Bio17-1 and RN1 were identified through CRISPRFinder (Grissa et al. 2007b). Then, M. parvicella CRISPR spacers and those in CRISPRdb from 3096 analyzed genomes were aligned to the assembled viromes by using BLASTn with the parameters suggested by CRISPRTarget (Biswas et al. 2013; Grissa et al. 2007a). For each phage genotype, the bacteria with the highest percent identity with a CRISPR spacer were considered as potential hosts (Edwards et al. 2016). 
Finally, the contigs with duplicated host predictions were assigned to a lowest common host ancestor, and the relative abundance of viral genotypes associated with specific bacterial genera was calculated in each virome. Using the same methods, except for the abundance calculation, phage-host predictions were also performed for the viromes (mainly deposited in the Metavir server) retrieved from different environments, including shallow sea (Bohai Sea, a depth of $26 \mathrm{~m}$ ), a deep abyss (ALOHA station in North Pacific Gyre, a depth of $4000 \mathrm{~m}$ ), human feces, estuary (Jiulong River), and a Singapore sludge plant (MG-RAST ID mgm4450221.3). Then, the MEGAN program was used to compare the host types predicted in each sample and perform principal coordinate analysis (Huson et al. 2011).

\section{Results}

\section{Bacterial community structure}

Six 16S rRNA gene libraries (two replicates for each sludge condition) with an average of $\sim 10,000$ pyrosequences per library were constructed to compare bacterial communities under different sludge conditions. Based on the QIIME pipeline analysis, the sludge bacterial communities consisted of five main phyla: Proteobacteria, Actinobacteria, Bacteroidetes, Firmicutes, and Chloroflexi (Fig. 1 and Table S1). The bulking sludge samples (ASB and ASR; SVI > $125 \mathrm{ml} / \mathrm{g}$ ) shared a similar bacterial community structure, dominated by Microthrix spp. (average 18.0 and $36.1 \%$ of pyrosequences in the ASB and ASR libraries, respectively) from the family
Microthrixaceae. In contrast, the non-bulking sludge (ASN) bacterial community was dominated by Anaerolineae species (10.7\%). Besides Microthrixaceae, several other bacterial families increased dramatically in the bulking sludge samples, including Chitinophagaceae (3.2-3.6\%), Intrasporangiaceae $(2.0-2.8 \%)$, Carnobacteriaceae $(1.0-4.2 \%)$, and Flavobacteriaceae $(1.2-2.5 \%)$. Interestingly, Nitrosomonadaceae (average $0.1-0.3$ and $0.8 \%$ in the bulking and non-bulking systems, respectively) and Nitrospiraceae (0.1-0.6 and 1.5\%), members of which are associated with nitrification, decreased significantly during sludge bulking (Fig. 1 and Table S1). Furthermore, classification based on the bulking and foaming bacteria database revealed that the non-bulking libraries contained numerous sequences related to Type0092 (predominant floc-stabilizing bacteria within Anaerolineae) (Speirs et al. 2009), whereas M. parvicella was prevalent in the bulking sludge libraries (Fig. S2) (Guo and Zhang 2012; Yoon et al. 2010).

\section{General analysis of viral metagenome}

About $18.4 \mathrm{~Gb}$ of high-quality sequencing data was generated, with an average $\sim 6.1 \mathrm{~Gb}$ data per sample. The obtained virome reads were analyzed through the MGRAST server. About $10 \%$ of annotations were assigned to viruses by the best-hit taxonomic classification. Although numerous annotations $(\sim 75 \%)$ were assigned to bacteria (mainly Burkholderiales), most of them shared homology with phage proteins, such as phage methylase, terminases, and integrases. According to the SEED classification, most annotations fell in the category "phages and
Fig. 1 Taxonomic profiles of bacterial communities. The unweighted pair group method with arithmetic mean tree shows the relationship among sludge samples. $A S N$ normal sludge, $A S R$ recovering sludge at the end stage of bulking, $A S B$ serious bulking sludge

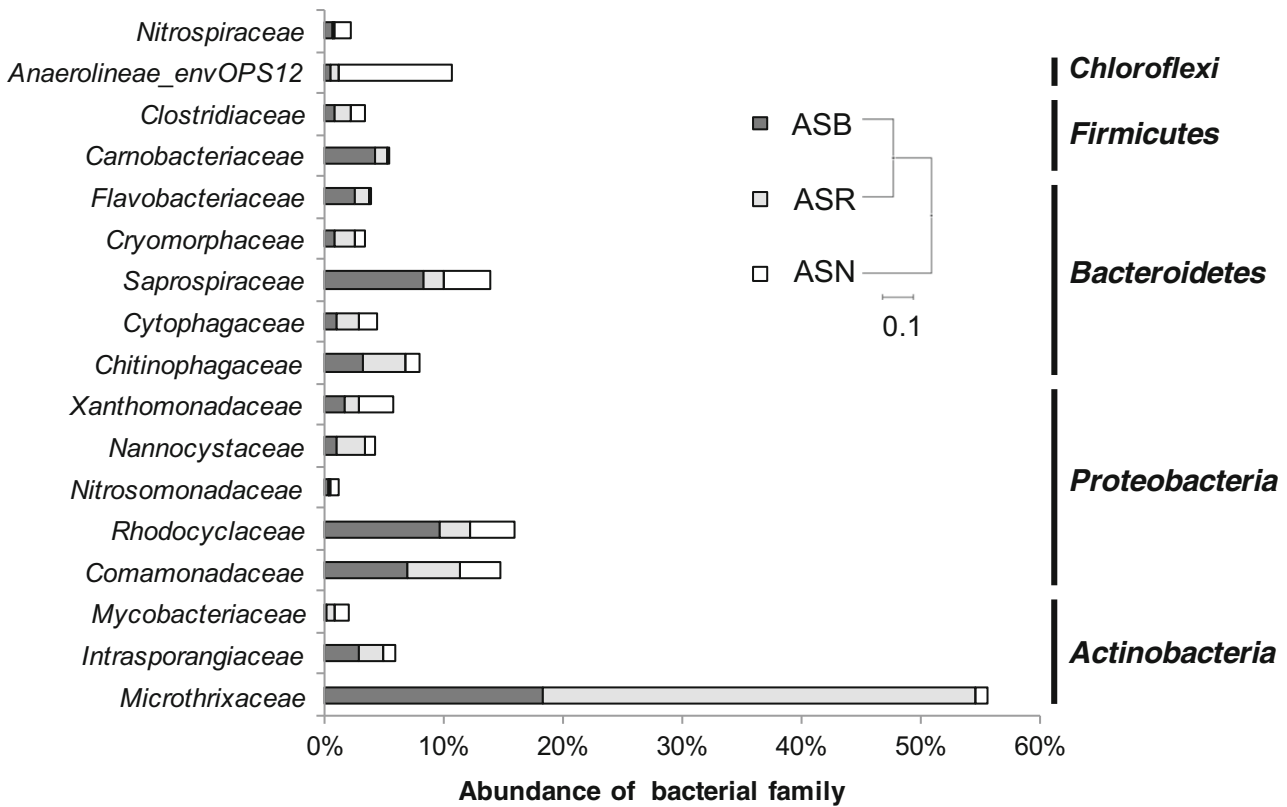


prophages" (Fig. S3a), reflecting the predominance of phages in viral communities. Based on the KEGG database, metabolic profiles were generally similar for all viromes (Fig. S3b). However, genes involved in carbohydrate metabolism were significantly enriched in the nonbulking virome (7\%) compared to the two bulking viromes $(2-3 \%)$. Most sequences in this group encoded GDPmannose 4, 6-dehydratase, which is associated with the glycosylation of viral capsid proteins (Tonetti et al. 2003). Principal coordinate analysis based on the NOG classification showed that the two bulking viromes (ASB and ASR) were grouped closely together (Fig. S4), and possibly encoded similar functional profiles.

The short sequencing reads were assembled into contigs, which represent viral genotypes in this study. The assembly efforts yielded between 40,131 and 65,010 contigs with lengths of over $500 \mathrm{bp}$. Nucleotide composition and tBLASTx-based similarity computation were used to compare the assembled viromes. Accordingly, the two bulking viromes shared a similar nucleotide composition (Fig. 2). To further compare the abundance distribution of viral genotypes in each virome, sequencing reads were mapped back to the assembled viromes. As a result, 7.5$9.5 \%$ of bulking reads were mapped to non-bulking contigs. In contrast, $14.4-19.8 \%$ of reads from the bulking viromes and only $4.3-5.9 \%$ of those from the non-bulking virome could be mapped to bulking contigs (Fig. 2). These

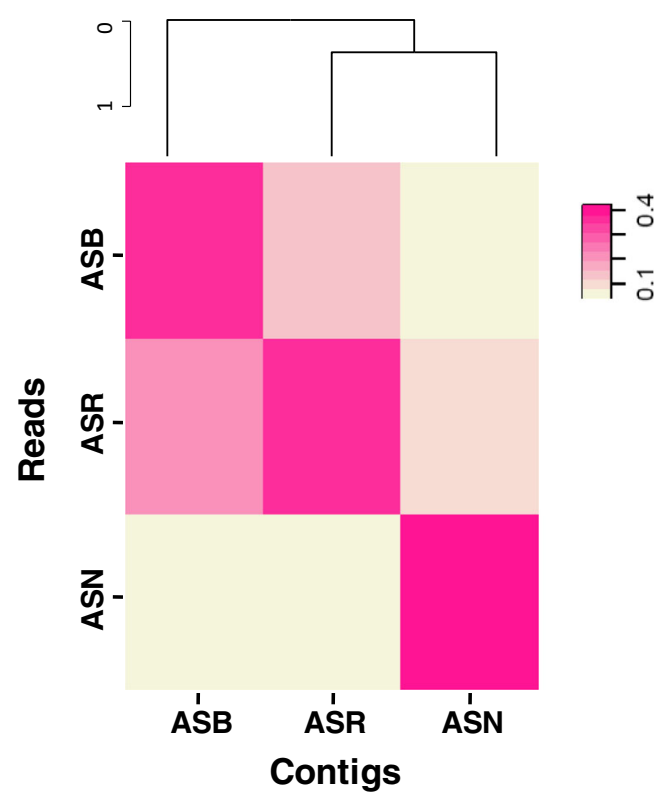

Fig. 2 Comparison among viromes generated from different sludge conditions. The clustering tree based on tetranucleotide comparisons shows the relationship among assembled viromes. The heatmap displays the alignment rate of sequencing reads mapped onto each assembled virome. $A S N$ normal sludge, $A S R$ recovering sludge at the end stage of bulking, $A S B$ serious bulking sludge results indicate elevated viral community similarity between bulking systems.

\section{Prediction of phage-host association}

Sequence homology and CRISPR-based methods might generate different predictions for phage-host associations (Edwards et al. 2016). Thus, the results of these different methods were combined to provide a more comprehensive host prediction. A total of 295 (out of 165,670) contigs were linked to the predicted hosts, and the abundance of these phage genotypes in each virome was calculated at the genus level of the corresponding host bacteria (Fig. 3). Most of the predicted host types were shared among bulking and nonbulking viral communities, but differed in terms of the relative abundance of the corresponding phage genotypes. The bulking viromes were enriched in phage genotypes associated with Accumulibacter, Acidovorax, Gordonia, Mesorhizobium, and Methylobacterium, whereas the most abundant phage genotypes in the non-bulking virome were associated with Bordetella spp. In addition, phage genotypes associated with filamentous Microthrix and nitrifiers (Nitrosomonas, Nitrobacter, and Nitrospira) also appeared in higher abundance in the bulking viromes.

Specifically, genetic homology between the obtained contigs and Refseq viral genomes identified 90 contigs with significant matches (BLASTn, $E$-value $<1 \mathrm{e}^{-90}$ ) to the genomes of phages that infected mainly Pseudomonas, Bordetella, Gordonia, Mycobacterium, and Burkholderia (Tables S2 and S3). Most of the matched contigs from the ASN virome (21/36) shared homology with Bordetella phages, whereas the ASB virome contained more contigs (16/37) associated with Pseudomonas phages.

Based on homology comparison (Edwards et al. 2016), a total of 124 contigs shared homology with bacterial genomes $\left(E\right.$-value $\left.<1 \mathrm{e}^{-90}\right)$. Most of the matched bacterial fragments fell in the prophage regions (Tables S2 and S3) (Arndt et al. 2016), suggesting that the corresponding phages may employ a lysogenic life cycle. Consistent with the above analysis, the nonbulking virome (ASN) contained substantially more contigs (14/40) homologous to Bordetella, whereas the two bulking viromes contained more contigs ( 6 in ASB and ASR, and 0 in ASN) associated with nitrifying bacteria, including ammoniaoxidizing Nitrosomonas and Nitrosococcus, and nitriteoxidizing Nitrobacter and Nitrospira. Notably, ASB presented many contigs (16/60) associated with denitrifying bacteria, including Alicycliphilus denitrificans, Hyphomicrobium denitrificans, and Thiobacillus denitrificans. Moreover, ASB contig23172, encoding the phage Gp37/68 protein (COG4422/PF07505), showed an (almost) exact match (956/957 bp) with the genome of M. parvicella Bio17-1. In addition, two contigs (ASR_contig36737 and ASN_contig22626) shared high sequence identity (526/ 
Fig. 3 Abundance distributions of phage genotypes and their corresponding host bacteria. The relative abundance of phage genotypes refers to the percentage of mapped reads/total reads in each virome. The abundance of "Candidatus Microthrix" in bulking bacterial communities is so high that it is represented by red stars. ASN normal sludge, $A S R$ recovering sludge at the end stage of bulking, $A S B$ serious bulking sludge

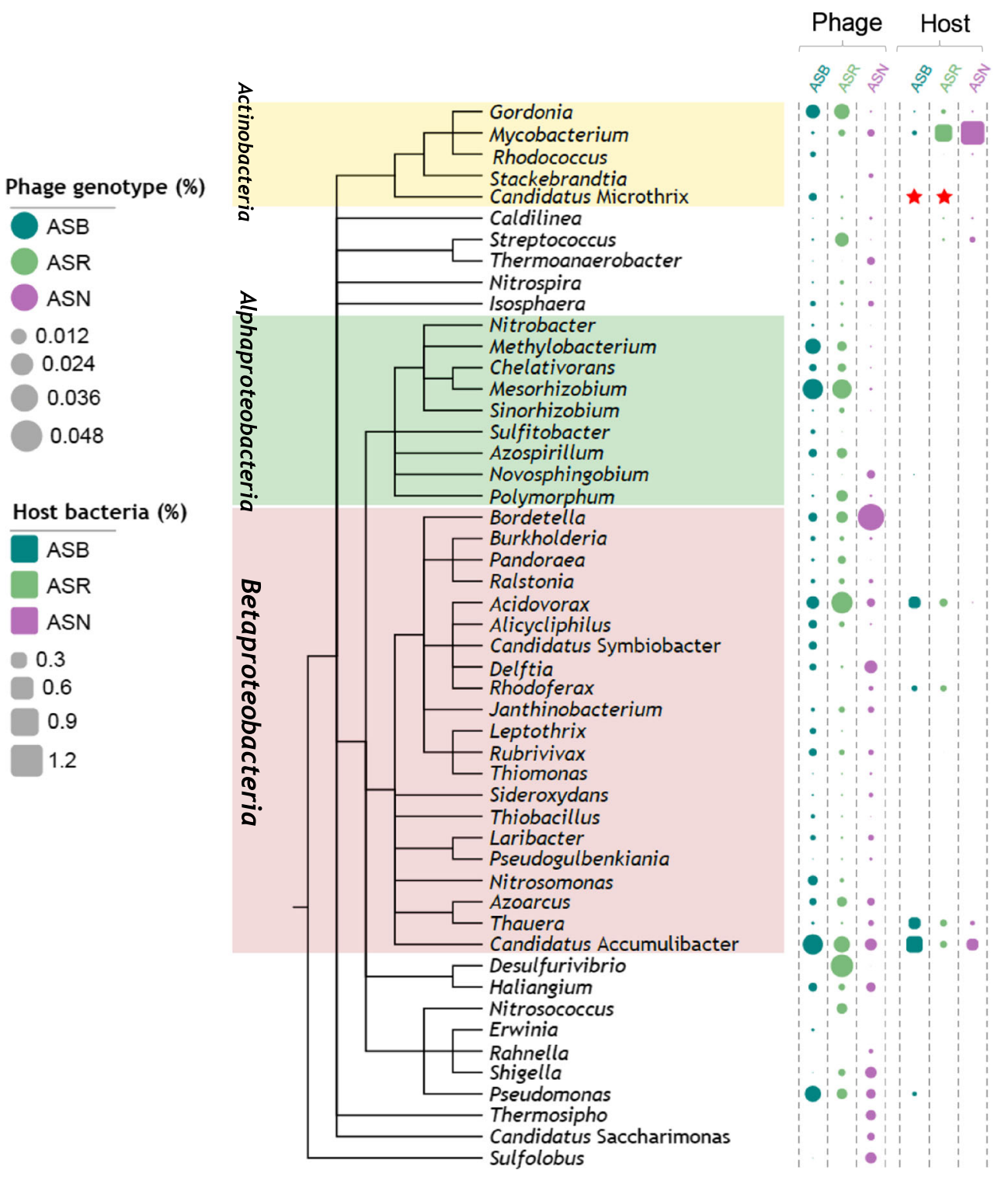

$527 \mathrm{bp}$ ) with the trimethoprim-resistant $d f r A 1$ gene of Shigella sonnei Ss046.

CRISPR analysis (comparison between contigs and CRISPR spacer sequences) found that most significant hits (99 contigs with no more than one mismatch, Tables S2 and S3), especially in the bulking viromes (ASB, 21/43; ASR, 13/ 31; ASN, 7/25), were associated with Accumulibacter phosphatis, a polyphosphate-accumulating organism frequently identified in wastewater treatment plants (Seviour et al. 2003). A number of contigs were significantly aligned to the spacers of denitrifying bacteria, such as Acidovorax, Haliangium, and Thauera (McIlroy et al. 2015). There was one ASB contig associated with nitrite-oxidizing "Candidatus Nitrospira defluvii". Notably, when three mismatches were allowed to improve sensitivity, five contigs derived from the bulking systems showed alignments with the CRISPR spacers from $M$. parvicella Bio17-1.

\section{Comparison of viromes from different environments}

To compare phage-host associations in different environments, host prediction was performed for virome data sets derived from various environments, including human feces, marine, estuary, and a tropical sludge plant (Figs. 4 and S5). The predicted host types in different environments differed significantly. Specifically, numerous contigs in the human feces virome were associated with Bacteroides and Ruminococcus, dominant bacterial genera in human gut microbiota (Lay et al. 2005; Zoetendal et al. 2002). Moreover, there were many contigs related to uncultured crAssphage, a Bacteroides phage predominant in human feces (Dutilh et al. 2014). The estuary virome contained many contigs associated with "Candidatus Pelagibacter," one of the most common microorganisms in oceans (Giovannoni et al. 2005). Alcanivorax and Vibrio, which occur naturally in seawater, 
Fig. 4 Principle coordinate analysis of viromes retrieved from different environments based on the predicted host taxonomy profile. $A S N$ normal sludge, $A S R$ recovering sludge at the end stage of bulking, $A S B$ serious bulking sludge
PCoA of Taxonomy profile, PC 1 vs PC 2 , stress $=0.53$, ecological index: BrayCurtis

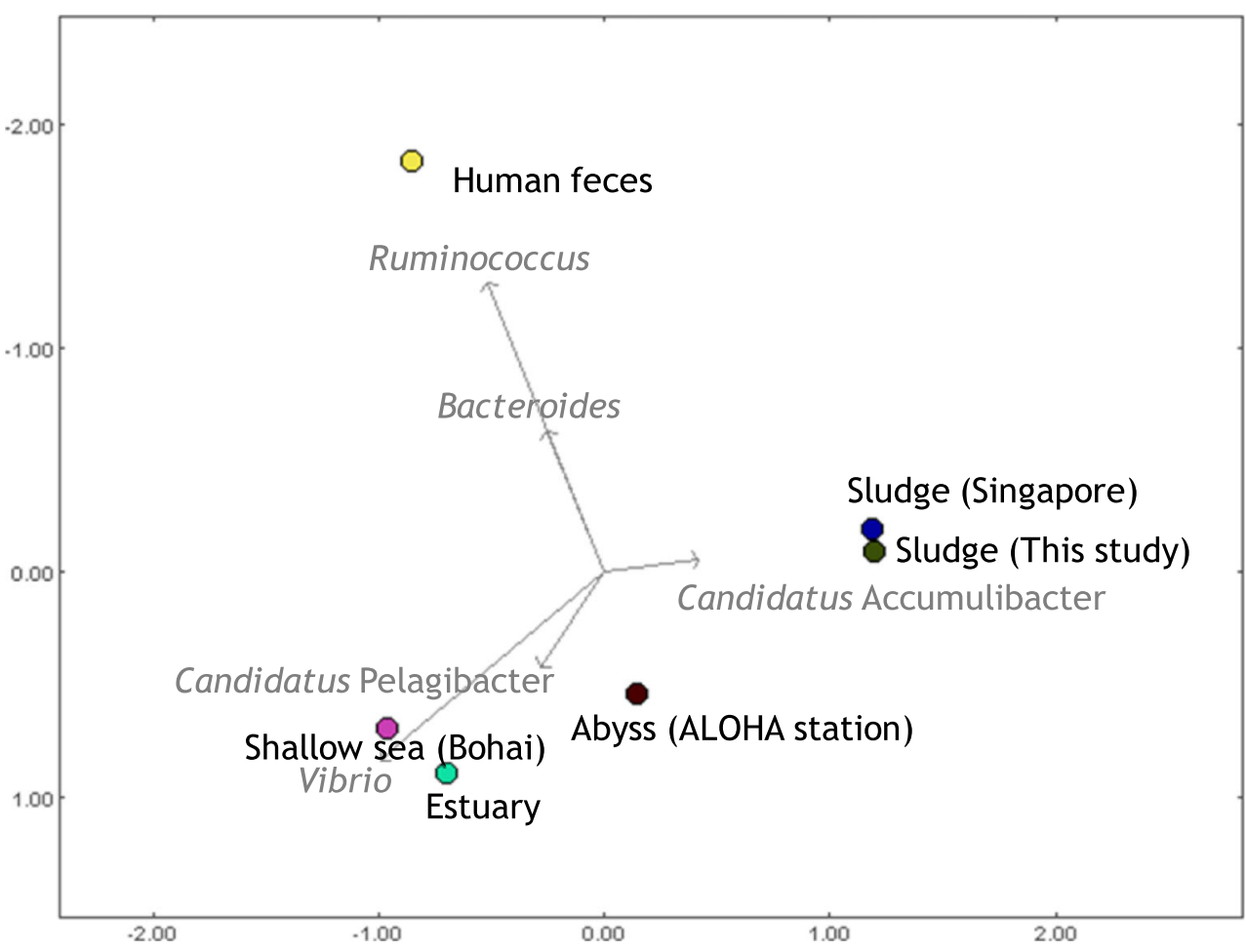

were the dominant predicted hosts associated with the marine viromes retrieved from a deep abyss (ALOHA station, $4000 \mathrm{~m}$ depth) and shallow sea (Bohai Sea, $26 \mathrm{~m}$ depth), respectively (Head et al. 2006; Thompson et al. 2004). In comparison, the sludge viromes retrieved from this studied plant and a Singapore sludge plant (Tamaki et al. 2012) exhibited more similar predicted host types, with Accumulibacter and Bordetella being the most frequent hosts (Seviour et al. 2003; Vuono et al. 2015).

\section{Discussion}

Pyrosequencing analysis revealed significant differences between bacterial composition of the bulking and non-bulking sludges, which were dominated by Microthrix spp. and Anaerolineae species, respectively (Figs. 1 and S2, Table S1). Overgrowth of $M$. parvicella during sludge bulking has been reported for the same plant in our previous study (Wang et al. 2014). Likewise, significant differences were observed between the viromes retrieved from the bulking and non-bulking sludge systems (Figs. 2 and 3), indicating that viral communities also experienced dramatic changes along with sludge bulking. It is interesting that despite a sampling interval of about 10 months, the two bulking samples showed similar bacterial community structure, and their viromes exhibited similar metabolic profiles, contig patterns, and predicted host types (Figs. 1, 2, and 3 and S4). Although daily or weekly fluctuations of viral species may occur (Needham et al. 2013; Rodriguez-Brito et al. 2010; Shapiro et al. 2010), this result indicate that the viral community in sludge systems can recover its structure and function profile, reflecting ecological resilience of microbial communities in the activated sludge plant. Furthermore, it is suggested that changes in viral and bacterial populations closely correlate with each other.

Corresponding to the distribution of Microthrix spp., all of the Microthrix-related viral contigs were retrieved from bulking systems, whereas none of the mapped read was derived from the non-bulking system (Table S3). Similarly, Acidovorax and Pseudomonas also increased dramatically in conjunction with their associated phage genotypes under sludge bulking conditions (Fig. 3, Table S1). The elevated growth of these host bacteria should promote the proliferation of corresponding phages during sludge bulking. Notably, despite the apparent dominance of Microthrix in the bulking sludges, abundance of Microthrix-associated viral contigs was low in the bulking viromes (Fig. 3 and Table S2). This may be ascribed to the scarcity of genetic information about phages in wastewater treatment plants. However, such unexpected phage-host abundance distribution, in which the most dominant host is associated with rare viruses, can be explained by the "kill the winner-cost of resistance (KtW-COR)" model. The COR implicates a negative correlation between the amounts of resources an organism can allocate to growth or to resistance. Given that $M$. parvicella is an extremely slow- 
growing filamentous organism with fine-tuned resource usage (Muller et al. 2014; Rossetti et al. 2005), it could allocate more resources to prevent viral lysis. This would make M. parvicella more resistant to phage predation and thereby might facilitate its dominance in bulking microbial assemblages.

The comparison among viromes derived from different environments revealed significant differences in predicted host types, with the most frequent hosts related to the typical or common bacteria in each environment (Figs. 4 and S5). This suggests specific viral community profiles for different habitats and also reflects close associations between phages and their bacterial hosts. In comparison, sludge viromes were characterized by containing numerous genotypes associated with Accumulibacter phosphatis clade IIA str. UW-1 (Figs. 4 and S5), which is important for phosphorous removal in biological sewage treatment systems (Wagner and Loy 2002). This suggests an abundance of $A$. phosphatis-related phages in sludge viral communities. A. phosphatis was reported to be under persistent predation pressure by phages in two enhanced biological phosphorus removal reactors, in which this species constituted up to $80 \%$ of the biomass (Kunin et al. 2008). However, in the present study, Accumulibacter spp. accounted for only no more than $1 \%$ of the pyrosequences in sludge bacterial communities (Table S1). These findings imply that Accumulibacter face strong phage predation pressure. According to the KtW-COR model, the virus population can be dominated by viruses infecting the less dominant but metabolically active hosts (normally $r$-strategists, capable of fast-growth but little resistance to viral lysis) and vice versa (Vage et al. 2013). Considering the continuously stable phosphate removal performance, it is possible that Accumulibacter is one of the most active bacterial populations in sludge systems, and thus may be kept in check by viral lysis.

Consistent with our previous studies (Wang et al. 2014), ammonia- and nitrite-oxidizing bacteria (AOB and $\mathrm{NOB}$ ), corresponding mainly to Nitrosomonadaceae and Nitrospiraceae, respectively, decreased significantly in the bulking systems as revealed by the pyrosequencing analysis (Table S1). Such shift may lead to the accumulation of ammonia and nitrite during sludge bulking. In contrast, phage genotypes associated with $\mathrm{AOB} / \mathrm{NOB}$ were identified more frequently and in higher abundance in the bulking viromes (Fig. 3; Tables S2 and S3); and some of them showed significant alignment to prophage regions within the genomes of nitrifiers, such as Nitrosomonas sp., "Candidatus Nitrospira defluvii," and Nitrobacter winogradskyi Nb-255 (Table S3). These findings suggest that bulking sludge systems are rich in nitrifier-related phage particles, whose members could be derived from prophage induction. Some stress factors have been found to cause prophage induction and consequent growth inhibition in Nitrosospira multiformis, a Nitrosomonadaceae AOB (Choi et al. 2010). So, it is possible that the frequent occurrence of nitrifier-related phages may be associated with prophage induction under sludge bulking conditions. While non-filamentous bacteria, including $\mathrm{AOB}$ and $\mathrm{NOB}$, can be washed out due to deflocculation of activated sludge (Wang et al. 2014), our findings suggest that phage-mediated lysis might also contribute to the loss of nitrifiers during sludge bulking.

It should be noted that many host types predicted on the basis of sludge viromes could not be identified in the bacterial communities in the present study. This included bacterial genera such as Bordetella, Methylobacterium, Desulfurivibrio, Azoarcus, and Delftia (Fig. 3 and Table S1). In particular, viral contigs corresponding to Bordetella appeared frequently in sludge viromes (Fig. S5 and Table S3) and constituted the most dominant phage genotype in the non-bulking viral community (Fig. 3). This is in line with a viral metagenomic study on an activated sludge plant in Singapore, which also reported abundant reads and contigs associated with Bordetella (Fig. S5) (Tamaki et al. 2012). Phages represented by these contigs probably infect relatives of the predicted hosts. To further determine the host identities associated with these contigs, future studies will benefit from emerging molecular tools, such as phageFISH and microfluidic digital PCR (Allers et al. 2013; Tadmor et al. 2011), with the combination of the gathered viral genetic information in this study.

Acknowledgments This work was funded by the Science Fund for Creative Research Groups of China (No. 51221892), the National Natural Science Foundation of China (No. 51378489 and 31170468), and the Special Corporation Foundation of University of Chinese Academy of Sciences (No. Y552023 Y00).

Author's contributions Yu Zhang, Ruyin Liu, and Rong Qi designed the research. Ruyin Liu, Rong Qi, Juan Wang, Yu Zhang, Xinchun Liu, and Min Yang performed the research. Simona Rossetti and Valter Tandoi contributed to new analytic tools. Ruyin Liu, Rong Qi, and Yu Zhang analyzed data and wrote the paper. Ruyin Liu and Rong Qi contributed equally to this work as co-first authors.

\section{Compliance with ethical standards}

Conflict of interest The authors declare that they have no conflict of interest.

Ethical approval This article does not contain any studies with human participants or animals performed by any of the authors.

\section{References}

Allers E, Moraru C, Duhaime MB, Beneze E, Solonenko N, BarreroCanosa J, Amann R, Sullivan MB (2013) Single-cell and population level viral infection dynamics revealed by phageFISH, a method to visualize intracellular and free viruses. Environ Microbiol 15(8): 2306-2318. doi:10.1111/1462-2920.12100 
Arndt D, Grant JR, Marcu A, Sajed T, Pon A, Liang Y, Wishart DS (2016) PHASTER: a better, faster version of the PHAST phage search tool. Nucleic Acids Res 44(W1):W16-W21. doi:10.1093/nar/gkw387

Barr JJ, Slater FR, Fukushima T, Bond PL (2010) Evidence for bacteriophage activity causing community and performance changes in a phosphorus-removal activated sludge. FEMS Microbiol Ecol 74(3): 631-642. doi:10.1111/j.1574-6941.2010.00967.x

Benitez-Paez A, Alvarez M, Belda-Ferre P, Rubido S, Mira A, Tomas I (2013) Detection of transient bacteraemia following dental extractions by 16S rDNA pyrosequencing: a pilot study. Plos One 8(3):e57782

Biswas A, Gagnon JN, Brouns SJ, Fineran PC, Brown CM (2013) CRISPRTarget: bioinformatic prediction and analysis of crRNA targets. RNA Biol 10(5):817-827. doi:10.4161/rna.24046

Caporaso JG, Kuczynski J, Stombaugh J, Bittinger K, Bushman FD, Costello EK, Fierer N, Pena AG, Goodrich JK, Gordon JI, Huttley GA, Kelley ST, Knights D, Koenig JE, Ley RE, Lozupone CA, McDonald D, Muegge BD, Pirrung M, Reeder J, Sevinsky JR, Turnbaugh PJ, Walters WA, Widmann J, Yatsunenko T, Zaneveld J, Knight R (2010) QIIME allows analysis of high-throughput community sequencing data. Nat Methods 7(5):335-336. doi:10.1038/ nmeth.f.303

Choi J, Kotay SM, Goel R (2010) Various physico-chemical stress factors cause prophage induction in Nitrosospira multiformis 25196-an ammonia oxidizing bacteria. Water Res 44(15):4550-4558. doi:10. 1016/j.watres.2010.04.040

de los Reyes FL (2010) Foaming. In: Seviour R, Nielsen PH (eds) Microbial ecology of activated sludge. IWA publishing, London, pp 215-258

Dutilh BE, Cassman N, McNair K, Sanchez SE, Silva GG, Boling L, Barr JJ, Speth DR, Seguritan V, Aziz RK, Felts B, Dinsdale EA, Mokili JL, Edwards RA (2014) A highly abundant bacteriophage discovered in the unknown sequences of human faecal metagenomes. Nat Commun 5:4498. doi: $10.1038 /$ ncomms 5498

Edwards RA, McNair K, Faust K, Raes J, Dutilh BE (2016) Computational approaches to predict bacteriophage-host relationships. FEMS Microbiol Rev 40(2):258-272. doi:10.1093/femsre/ fuv048

Giovannoni SJ, Tripp HJ, Givan S, Podar M, Vergin KL, Baptista D, Bibbs L, Eads J, Richardson TH, Noordewier M, Rappe MS, Short JM, Carrington JC, Mathur EJ (2005) Genome streamlining in a cosmopolitan oceanic bacterium. Science 309(5738):12421245. doi:10.1126/science. 1114057

Grissa I, Vergnaud G, Pourcel C (2007a) The CRISPRdb database and tools to display CRISPRs and to generate dictionaries of spacers and repeats. BMC Bioinf 8:172. doi:10.1186/1471-2105-8-172

Grissa I, Vergnaud G, Pourcel C (2007b) CRISPRFinder: a web tool to identify clustered regularly interspaced short palindromic repeats. Nucleic Acids Res 35(web server issue):W52-W57. doi:10.1093/ $\mathrm{nar} / \mathrm{gkm} 360$

Guo F, Zhang T (2012) Profiling bulking and foaming bacteria in activated sludge by high throughput sequencing. Water Res 46(8):27722782. doi:10.1016/j.watres.2012.02.039

Head IM, Jones DM, Roling WFM (2006) Marine microorganisms make a meal of oil. Nat Rev Micro 4(3):173-182

Henze M, van Loosdrecht MCM, Ekama GA, Brdjanovic D (2008) Biological wastewater treatment: principles, modelling and design. IWA publishing, London

Huson DH, Mitra S, Ruscheweyh HJ, Weber N, Schuster SC (2011) Integrative analysis of environmental sequences using MEGAN4. Genome Res 21(9):1552-1560. doi:10.1101/gr.120618.111

Jenkins D, Richard MG, Daigger GT (2004) Manual on the causes and control of activated sludge bulking, foaming, and other solids separation problems. IWA Publishing, London

Kunin V, He S, Warnecke F, Peterson SB, Martin HG, Haynes M, Ivanova N, Blackall LL, Breitbart M, Rohwer F, McMahon KD, Hugenholtz P (2008) A bacterial metapopulation adapts locally to phage predation despite global dispersal. Genome Res 18(2)):293297. doi:10.1101/Gr.6835308

Langmead B, Salzberg SL (2012) Fast gapped-read alignment with Bowtie 2. Nat Methods 9(4):357-359. doi:10.1038/nmeth.1923

Lay C, Rigottier-Gois L, Holmstrom K, Rajilic M, Vaughan EE, de Vos WM, Collins MD, Thiel R, Namsolleck P, Blaut M, Dore J (2005) Colonic microbiota signatures across five northern European countries. Appl Environ Microbiol 71(7):4153-4155. doi:10.1128/AEM. 71.7.4153-4155.2005

Li R, Zhu H, Ruan J, Qian W, Fang X, Shi Z, Li Y, Li S, Shan G, Kristiansen K, Li S, Yang H, Wang J, Wang J (2010) De novo assembly of human genomes with massively parallel short read sequencing. Genome Res 20(2):265-272. doi:10.1101/gr.097261.109

McIlroy SJ, Saunders AM, Albertsen M, Nierychlo M, McIlroy B, Hansen AA, Karst SM, Nielsen JL, Nielsen PH (2015) MiDAS: the field guide to the microbes of activated sludge. Database 2015: bav062. doi:10.1093/database/bav062

Meyer F, Paarmann D, D'Souza M, Olson R, Glass EM, Kubal M, Paczian T, Rodriguez A, Stevens R, Wilke A, Wilkening J, Edwards RA (2008) The metagenomics RAST server-a public resource for the automatic phylogenetic and functional analysis of metagenomes. BMC Bioinf 9:386. doi:10.1186/1471-2105-9-386

Modi SR, Lee HH, Spina CS, Collins JJ (2013) Antibiotic treatment expands the resistance reservoir and ecological network of the phage metagenome. Nature 499(7457):219-223. doi:10.1038/ Nature 12212

Muller EE, Pinel N, Laczny CC, Hoopmann MR, Narayanasamy S, Lebrun LA, Roume H, Lin J, May P, Hicks ND, Heintz-Buschart A, Wampach L, Liu CM, Price LB, Gillece JD, Guignard C, Schupp JM, Vlassis N, Baliga NS, Moritz RL, Keim PS, Wilmes P (2014) Community-integrated omics links dominance of a microbial generalist to fine-tuned resource usage. Nat Commun 5:5603. doi:10. 1038/ncomms6603

Needham DM, Chow CE, Cram JA, Sachdeva R, Parada A, Fuhrman JA (2013) Short-term observations of marine bacterial and viral communities: patterns, connections and resilience. ISME J 7(7): 1274-1285. doi:10.1038/ismej.2013.19

Pagarete A, Chow CE, Johannessen T, Fuhrman JA, Thingstad TF, Sandaa RA (2013) Strong seasonality and interannual recurrence in marine myovirus communities. Appl Environ Microbiol 79(20): 6253-6259. doi:10.1128/AEM.01075-13

Parsley LC, Consuegra EJ, Thomas SJ, Bhavsar J, Land AM, Bhuiyan NN, Mazher MA, Waters RJ, Wommack KE, Harper WF Jr, Liles MR (2010) Census of the viral metagenome within an activated sludge microbial assemblage. Appl Environ Microbiol 76(8): 2673-2677. doi:10.1128/AEM.02520-09

Petrovski S, Seviour RJ, Tillett D (2011) Genome sequence and characterization of the Tsukamurella bacteriophage TPA2. Appl Environ Microbiol 77(4):1389-1398. doi:10.1128/Aem.01938-10

Rodriguez-Brito B, Li LL, Wegley L, Furlan M, Angly F, Breitbart M, Buchanan J, Desnues C, Dinsdale E, Edwards R, Felts B, Haynes M, Liu H, Lipson D, Mahaffy J, Martin-Cuadrado AB, Mira A, Nulton J, Pasic L, Rayhawk S, Rodriguez-Mueller J, Rodriguez-Valera F, Salamon P, Srinagesh S, Thingstad TF, Tran T, Thurber RV, Willner D, Youle M, Rohwer F (2010) Viral and microbial community dynamics in four aquatic environments. ISME J 4(6): 739-751. doi:10.1038/Ismej.2010.1

Rossetti S, Tomei MC, Nielsen PH, Tandoi V (2005) "Microthrix parvicella", a filamentous bacterium causing bulking and foaming in activated sludge systems: a review of current knowledge. FEMS Microbiol Rev 29(1):49-64. doi:10.1016/j.femsre.2004.09.005

Roux S, Tournayre J, Mahul A, Debroas D, Enault F (2014) Metavir 2: new tools for viral metagenome comparison and assembled virome analysis. BMC Bioinf 15:76. doi:10.1186/1471-2105-15-76

Sakowski EG, Munsell EV, Hyatt M, Kress W, Williamson SJ, Nasko DJ, Polson SW, Wommack KE (2014) Ribonucleotide reductases reveal 
novel viral diversity and predict biological and ecological features of unknown marine viruses. Proc Natl Acad Sci U S A 111(44):1578615791. doi:10.1073/pnas.1401322111

Schloss PD, Westcott SL, Ryabin T, Hall JR, Hartmann M, Hollister EB, Lesniewski RA, Oakley BB, Parks DH, Robinson CJ, Sahl JW, Stres B, Thallinger GG, Van Horn DJ, Weber CF (2009) Introducing mothur: open-source, platform-independent, community-supported software for describing and comparing microbial communities. Appl Environ Microbiol 75(23):7537-7541. doi:10.1128/AEM.01541-09

Seviour RJ, Mino T, Onuki M (2003) The microbiology of biological phosphorus removal in activated sludge systems. FEMS Microbiol Rev 27(1):99-127

Shapiro OH, Kushmaro A (2011) Bacteriophage ecology in environmental biotechnology processes. Curr Opin Biotechnol 22(3):449-455. doi:10.1016/j.copbio.2011.01.012

Shapiro OH, Kushmaro A, Brenner A (2010) Bacteriophage predation regulates microbial abundance and diversity in a full-scale bioreactor treating industrial wastewater. ISME J 4(3):327-336. doi:10. 1038/ismej.2009.118

Speirs L, Nittami T, McIlroy S, Schroeder S, Seviour RJ (2009) Filamentous bacterium Eikelboom type 0092 in activated sludge plants in Australia is a member of the phylum Chloroflexi. Appl Environ Microbiol 75(8):2446-2452. doi:10.1128/AEM.02310-08

Stern A, Mick E, Tirosh I, Sagy O, Sorek R (2012) CRISPR targeting reveals a reservoir of common phages associated with the human gut microbiome. Genome Res 22(10):1985-1994. doi:10.1101/gr. 138297.112

Suttle CA (2007) Marine viruses - major players in the global ecosystem. Nat Rev Microbiol 5(10):801-812. doi:10.1038/nrmicro1750

Tadmor AD, Ottesen EA, Leadbetter JR, Phillips R (2011) Probing individual environmental bacteria for viruses by using microfluidic digital PCR. Science 333(6038):58-62. doi:10.1126/science.1200758

Tamaki H, Zhang R, Angly FE, Nakamura S, Hong PY, Yasunaga T, Kamagata Y, Liu WT (2012) Metagenomic analysis of DNA viruses in a wastewater treatment plant in tropical climate. Environ Microbiol 14(2):441-452. doi:10.1111/j.1462-2920.2011.02630.x

Thompson JR, Randa MA, Marcelino LA, Tomita-Mitchell A, Lim E, Polz MF (2004) Diversity and dynamics of a north atlantic coastal Vibrio community. Appl Environ Microbiol 70(7):4103-4110. doi: 10.1128/AEM.70.7.4103-4110.2004

Thurber RV, Haynes M, Breitbart M, Wegley L, Rohwer F (2009) Laboratory procedures to generate viral metagenomes. Nat Protoc 4(4):470-483. doi:10.1038/nprot.2009.10
Tonetti M, Zanardi D, Gurnon JR, Fruscione F, Armirotti A, Damonte G, Sturla L, De Flora A, Van Etten JL (2003) Paramecium bursaria Chlorella virus 1 encodes two enzymes involved in the biosynthesis of GDP-L-fucose and GDP-D-rhamnose. J Biol Chem 278(24): 21559-21565. doi:10.1074/jbc.M301543200

Vage S, Storesund JE, Thingstad TF (2013) Adding a cost of resistance description extends the ability of virus-host model to explain observed patterns in structure and function of pelagic microbial communities. Environ Microbiol 15(6):1842-1852. doi:10.1111/14622920.12077

Vuono DC, Benecke J, Henkel J, Navidi WC, Cath TY, Munakata-Marr J, Spear JR, Drewes JE (2015) Disturbance and temporal partitioning of the activated sludge metacommunity. ISME J 9(2):425-435. doi: 10.1038/ismej.2014.139

Wagner M, Loy A (2002) Bacterial community composition and function in sewage treatment systems. Curr Opin Biotechnol 13(3):218-227. doi:10.1016/S0958-1669(02)00315-4

Wang J, Li Q, Qi R, Tandoi V, Yang M (2014) Sludge bulking impact on relevant bacterial populations in a full-scale municipal wastewater treatment plant. Process Biochem 49(12):2258-2265. doi:10.1016/j. procbio.2014.08.005

Wang Q, Garrity GM, Tiedje JM, Cole JR (2007) Naive Bayesian classifier for rapid assignment of rRNA sequences into the new bacterial taxonomy. Appl Environ Microbiol 73(16):5261-5267. doi:10. 1128/AEM.00062-07

Wilke A, Harrison T, Wilkening J, Field D, Glass EM, Kyrpides N, Mavrommatis K, Meyer F (2012) The M5nr: a novel nonredundant database containing protein sequences and annotations from multiple sources and associated tools. BMC Bioinf 13:141. doi:10.1186/1471-2105-13-141

Wu Q, Liu WT (2009) Determination of virus abundance, diversity and distribution in a municipal wastewater treatment plant. Water Res 43(4):1101-1109. doi:10.1016/j.watres.2008.11.039

Yoon DN, Park SJ, Kim SJ, Jeon CO, Chae JC, Rhee SK (2010) Isolation, characterization, and abundance of filamentous members of Caldilineae in activated sludge. J Microbiol 48(3):275-283. doi: 10.1007/s12275-010-9366-8

Zoetendal EG, Ben-Amor K, Harmsen HJ, Schut F, Akkermans AD, de Vos WM (2002) Quantification of uncultured Ruminococcus obeum-like bacteria in human fecal samples by fluorescent in situ hybridization and flow cytometry using $16 \mathrm{~S}$ rRNA-targeted probes. Appl Environ Microbiol 68(9):4225-4232 